\title{
EFEITO DO PROCESSAMENTO TÉRMICO E DA FORMA FÍSICA DE DIETAS PARA LEITÕES NO PERÍODO DE CRECHE
}

\author{
(Effects of processing and the physical form of diets for nursery piglets) \\ ${ }^{1}$ Leopoldo Malcorra de Almeida, ${ }^{1}$ Geovani Costa Senger, ${ }^{1}$ Vitor Augusto Bernardini Zavelinski, ${ }^{1}$ Katiucia \\ Cristine Sonalio, ${ }^{1}$ Isabella de Camargo Dias, ${ }^{1}$ Letícia Dzierva, ${ }^{2}$ Alex Maiorka \\ ${ }^{1}$ Universidade Federal do Paraná, Curitiba, PR, Brasil. ${ }^{2}$ Professor Associado do Departamento de Zootecnia, \\ Universidade Federal do Paraná, Curitiba, PR, Brasil. \\ *Correspondência: almeidamleopoldo@gmail.com
}

Resumo: $O$ experimento foi conduzido para avaliar o efeito da forma física e do processo térmico (peletização) da ração sobre o desempenho e o desperdício de ração de leitões durante o período de creche. Foram utilizados 40 leitões machos castrados e fêmeas, dos 21 a 62 dias de idade, distribuídos em delineamento de blocos casualizados de acordo com os seguintes tratamentos: $\mathrm{Fa}$ - dieta farelada e Pe - dieta peletizada. As dietas a base de milho e farelo de soja foram formuladas a fim de atender as exigências nutricionais dos animais de creche, sendo divididas em 3 fases: pré-inicial (21 aos 28 dias de idade); pré-inicial 2 (28 a 42 dias de idade) e inicial (42 a 62 dias de idade). $O$ processo de peletização ocorreu em uma peletizadora a vapor de matriz com furos de diâmetro de $4 \mathrm{~mm}$. O tempo de condicionamento foi de 7 segundos com pressão de $1,2 \mathrm{kgf} / \mathrm{cm}^{2}$ e temperatura de 50 a $60^{\circ} \mathrm{C}$, para as deitas pré-iniciais, e 70 a $80^{\circ} \mathrm{C}$ para a dieta inicial. Após o processo de peletização as dietas foram secas e resfriadas até atingirem temperatura de $32^{\circ} \mathrm{C}$. Os animais foram pesados aos 21 e 62 dias de idade para avaliação do ganho de peso diário (GPD). Para determinar o consumo de ração diário (CRD) e conversão alimentar (CA), tanto a ração fornecida como a sobra foram pesadas. O desperdício de ração foi avaliado nas primeiras três semanas pós desmame. Os dados foram analisados por modelos lineares generalizados mistos, considerando os blocos (peso inicial e sexo) como efeito aleatório e a baia como unidade experimental, totalizando dois tratamentos com 10 repetições de dois animais cada. Não foi verificado diferença $(P=0,058$; $S E M=20,2)$ para o $C R D$ dos animais entre as diferentes dietas, sendo $696 \mathrm{~g}$ de consumo para $\mathrm{Fa}$ e $653 \mathrm{~g}$ para $\mathrm{Pe}$, no entanto, os animais recebendo a dieta $\mathrm{Fa}$ apresentaram desperdício $(\mathrm{P}<0,01 ; \mathrm{SEM}=0,021)$ de $57 \%$ a mais $(200,9 \mathrm{~g}$ vs. $87,4 \mathrm{~g} / \mathrm{animal})$ em relação aos leitões consumindo a dieta $\mathrm{Pe}$, durante o período avaliado. O GPD dos animais não foi influenciado $(P=0,119, S E M=14,7)$ pelo processamento térmico da dieta (Fa: $408 \mathrm{~g}$ vs. Pe: $437 \mathrm{~g}$ ), entretanto, este processo influenciou a $C A$ dos animais $(P<0,01 ; S E M=0,023)$, onde os leitões que receberam $\mathrm{Pe}(1,524)$ foram 9,2\% mais eficientes em relação aos consumindo $\mathrm{Fa}(1,680)$. Em conclusão o uso de dietas peletizadas diminuiu o desperdício de ração dos animais e melhorou o desempenho de suínos machos e fêmeas durante o período de creche.

Palavras-chaves: desperdício; desempenho; suínos.

\section{Agradecimentos}

O presente trabalho foi realizado com apoio da Coordenação de Aperfeiçoamento de Pessoal de Nível Superior - Brasil (CAPES) - Código de Financiamento 001.

\section{Nota}

O projeto foi aprovado pela Comissão de Ética no Uso de Animais do setor de Ciências Agrárias da Universidade Federal do Paraná. 